\title{
Effect of heat treatment in sulfur on structural, optical and electrical properties of thermally evaporated $\mathrm{In}_{2} \mathrm{~S}_{3}$ thin films
}

\author{
M.S. Tivanov ${ }^{a, *}$, I.A. Svito ${ }^{a}$, S. Rasool ${ }^{b}$, K. Saritha ${ }^{\mathrm{b}}$, K.T. Ramakrishna Reddy ${ }^{\text {b, }}$, V. \\ F. Gremenok ${ }^{\mathrm{c}}$ \\ ${ }^{\text {a }}$ Faculty of Physics, Belarusian State University, Nezavisimosti 4 av., 220030 Minsk, Belarus \\ ${ }^{\mathrm{b}}$ Solar Photovoltaic Laboratory, Department of Physics, Sri Venkateswara University, Tirupati 517 502, Andhra Pradesh, India \\ ${ }^{\mathrm{c}}$ Scientific and Practical Materials Research Centre, National Academy of Sciences, 220072 Minsk, Belarus
}

\section{A R T I C L E I N F O}

\section{Keywords:}

$\mathrm{In}_{2} \mathrm{~S}_{3}$ films

Thermal evaporation

Sulfur annealing

Structure

Optical

Electrical

\begin{abstract}
A B S T R A C T
Crystallinity, optical band gap, resistivity and photoresponse of thermally evaporated $\operatorname{In}_{2} \mathrm{~S}_{3}$ thin films deposited at a temperature of $350{ }^{\circ} \mathrm{C}$ and further annealed in sulfur vapour at different temperature range of $200-300{ }^{\circ} \mathrm{C}$ is investigated. It is observed that with an increase of annealing temperature, predominantly $\beta$ - $\operatorname{In}_{2} \mathrm{~S}_{3}$ phase is formed and the optical band gap for indirect allowed transitions increases from $1.6 \mathrm{eV}$ to $2.0 \mathrm{eV}$ and for direct allowed transitions from $2.3 \mathrm{eV}$ to $2.7 \mathrm{eV}$. The electrophysical properties indicate that the activation mechanism of conductivity with an activation energy in the range of $0.5-0.73 \mathrm{eV}$, which is typical for the presence of indium vacancies in the $\beta$ - $\operatorname{In}_{2} S_{3}$ crystal structure and for the replacement of sulfur by oxygen atoms. It is also noted that sulfur annealing at temperatures of $250-300{ }^{\circ} \mathrm{C}$ leads to an increase in the conductivity and photosensitivity of films, which is suitable for photovoltaic applications.
\end{abstract}

\section{Introduction}

Indium sulfide $\left(\operatorname{In}_{2} S_{3}\right)$ is one of the potential materials used in advanced solar cells, as buffer/window layer in $\mathrm{Cu}(\mathrm{In}, \mathrm{Ga}) \mathrm{Se}_{2}$, $\mathrm{Cu}_{2} \mathrm{ZnSnS}{ }_{4}$ and $\mathrm{Sb}_{2} \mathrm{~S}_{3}$ based thin film solar cells (Spiering et al., 2016; Lee and Yang, 2021; Lugo-Loredo et al., 2014; Shi et al., 2021), as an electron transport layer (ETL) in perovskite solar cells (Yang et al., 2019; Hou et al., 2017) and as a photosensitizer in sensitized solar cells (Yang et al., 2015; Zhang et al., 2014) due to its high stability at room temperature, transparency in a wide wavelength range, less toxicity of its constituent elements and also photosensitive nature. The record conversion efficiency of $18.2 \%$ was achieved using thermally evaporated $\mathrm{In}_{2} \mathrm{~S}_{3}$ films as buffer layer in $\mathrm{Cu}(\mathrm{In}, \mathrm{Ga}) \mathrm{Se}_{2}$-based thin film solar cells (Spiering et al., 2016), which is close to $22.6 \%$ efficiency achieved using toxic CdS as buffer layer in these cells (Jackson et al., 2016). Shi et al. (Shi et al., 2021) was also able to achieve improved conversion efficiency of $\mathrm{Sb}_{2} \mathrm{~S}_{3}$-based solar cell by introducing $\operatorname{In}_{2} \mathrm{~S}_{3}$ as buffer layer between $\mathrm{TiO}_{2}$ and $\mathrm{Sb}_{2} \mathrm{~S}_{3}$ layers that can reduce the charge recombination and enhanced the electron lifetime. Further, $\operatorname{In}_{2} \mathrm{~S}_{3}$ is used as a photo-anode in photoelectrochemical (PEC) cells for hydrogen production (Wang et al., 2020). Moreover, it can be used in Li-ion batteries ( $\mathrm{Gu}$ and Wang, 2014), gas sensor (Souissi et al., 2018; Souissi et al., 2019; Souissi et al., 2020; Souissi et al., 2020) and biosensor (Nagesh et al., 2001; Li et al., 2020) applications.

Indium sulfide has three different structural forms: $\alpha-\operatorname{In}_{2} S_{3}$ (defective cubic), $\beta-\operatorname{In}_{2} S_{3}$ (defective tetragonal) and $\gamma$ - $\operatorname{In}_{2} S_{3}$ (layered hexagonal) (Lee et al., 2008; Pistor et al., 2016). Crystalline $\beta$ - $\operatorname{In}_{2} S_{3}$ is an n-type semiconductor with direct band gap energy varies from $1.8 \mathrm{eV}$ to $2.4 \mathrm{eV}$ depending on its composition and deposition conditions (Sanz et al., 2013; Bouabid et al., 2004; Ji et al., 2015; Nehra et al., 2015). It is the most stable compound at room temperature (Pistor et al., 2016).

The $\alpha$-modification of $\operatorname{In}_{2} \mathrm{~S}_{3}$ is usually stable at temperatures above $420^{\circ} \mathrm{C}$. However, in the case when higher annealing rates or deficiency of $S$ atoms prevail during the synthesis process, it is possible to obtain samples of $\alpha-\operatorname{In}_{2} S_{3}$ phase that are stable even at room temperature (Sandoval-Paz et al., 2005). A high-temperature trigonal $\gamma$ - $\operatorname{In}_{2} S_{3}$ modification is stable at temperatures above $754{ }^{\circ} \mathrm{C}$. Nevertheless, the researchers showed that the addition of 5 at. \% As or Sb or other elements of V-group leads to the stabilization of $\gamma$ - $\operatorname{In}_{2} \mathrm{~S}_{3}$ phase at room temperature (Diehl et al., 1976; Choe et al., 2001).

Defect characteristics of $\operatorname{In}_{2} \mathrm{~S}_{3}$ structure violate the periodicity of the crystal lattice potential that leads to the appearance of allowed local

\footnotetext{
* Corresponding authors.

E-mail addresses: michael.tivanov@gmail.com (M.S. Tivanov), ktrkreddy@gmail.com (K.T. Ramakrishna Reddy).
} 
states in the optical band gap of the semiconductor, which can participate in the generation and recombination of non-equilibrium charge carriers. In this study, we observed the effect of subsequent heat treatment in sulfur vapor on the structure, phase composition, optical and electrophysical parameters of $\operatorname{In}_{2} S_{3}$ films obtained by the vacuum thermal evaporation.

\section{Experimental}

$\mathrm{In}_{2} \mathrm{~S}_{3}$ films were prepared using vacuum thermal evaporation technique (HHV BC300 model) using $\mathrm{In}_{2} \mathrm{~S}_{3}$ powder (Sigma Aldrich, $99.999 \%$ purity) as a source material. The films were deposited on soda lime glass substrates at a temperature of $350{ }^{\circ} \mathrm{C}$ and annealed for $1 \mathrm{~h}$ in sulfur vapor at temperatures $T_{\mathrm{s}}=200{ }^{\circ} \mathrm{C}, 250^{\circ} \mathrm{C}$ and $300{ }^{\circ} \mathrm{C}$.

A high-quality $\beta-\operatorname{In}_{2} S_{3}$ crystal was used as a reference sample in the study of Raman spectroscopy and photoluminescence of thin films. This $\beta$-In ${ }_{2} \mathrm{~S}_{3}$ crystal was obtained by the Bridgman - Stockbarger method from initially ground into powder polycrystalline ingots synthesized by the two-temperature method from elementary components (grade V4). A detailed description of the synthesis technique and conditions is presented in the works (Bodnar and Gremenok, 2011; Bodnar and Polubok, 2014).

The surface morphology and cross-sectional view of the films were investigated by S-806 (Hitachi) scanning electron microscope (SEM). The chemical composition was determined by energy dispersive X-ray (EDX) analysis using a CAMECA SX-100. The structural characteristics of the samples were analyzed by using Ultima IV (Rigaku) X-ray diffractometer in the grazing incidence diffraction geometry (GIXD) at 1 degree of incident X-rays with $\mathrm{Cu} K \alpha$ radiation source $(\lambda=1.54078 \AA$ ).

The transmission and specular reflection spectra of the films were obtained using Photon RT (Essent Optics) spectrophotometer in the wavelength range of $400-2400 \mathrm{~nm}$ with spectral resolution better than $4 \mathrm{~nm}$ using unpolarized light at room temperature.

Room-temperature Raman and PL spectra, as well as lowtemperature PL spectra, were recorded by a high-resolution Raman/PL spectrometer Nanofinder HE (LOTIS TII). Solid-state lasers were used as excitation sources ( $532 \mathrm{~nm}$ for Raman and $355 \mathrm{~nm}$ for PL measurement) and the excitation region diameter was about $2 \mu \mathrm{m}$. The power of the laser radiation incident on the sample was attenuated to few tenths of milli Watt in order to avoid its thermal damage and the spectral resolution was better than $2.5 \mathrm{~cm}^{-1}$. The signal accumulation time was $60 \mathrm{~s}$ and a cooled silicon CCD matrix was used as a photodetector. During the low-temperature PL measurements, the samples were studied in a vacuum (less than $5 \times 10^{-4} \mathrm{~Pa}$ ) temperature-controlled cell with a setting accuracy of $\pm 0.05 \mathrm{~K}$.

To study the electrical and photoelectrical properties of $\operatorname{In}_{2} \mathrm{~S}_{3}$ thin films, $3 \times 2 \mathrm{~mm}^{2}$ samples were prepared. The electrical measurements were carried out by the 2-probe method, for which the contacts to the samples were made by soldering with silver paste (Silberleitlack Nr. $530042 \mathrm{GmbH}$ ), followed by drying under atmospheric conditions for one day. The distance between the electrical contacts was in the range of $0.2-0.5 \mathrm{~mm}$. Conductance measurement of the films was carried out in the dark condition (after exposure for several days).

The temperature dependences of conductivity of films were measured using Keithley 2400 source-meter. A high-temperature vacuum chamber was used to measure the resistance, while the residual pressure in the chamber was $5 \mathrm{~Pa}$. A platinum resistance thermometer PT-100 was used to measure the temperature in the range, 300-450 K with accuracy better than $0.5 \mathrm{~K}$. The Lake Shore 332 controller was used to adjust and control the temperature. The temperature dependent resistance was measured during cooling at a rate of $2{ }^{\circ} \mathrm{C} / \mathrm{min}$ of preheated samples to a temperature of $450 \mathrm{~K}$. This algorithm for measuring the temperature dependences of conductivity ensured the reproducibility of the measurement results.

Photoconductance measurement was carried out under illumination with a ProLight PM6B-3LFx LED with a wavelength of $\lambda=465 \mathrm{~nm}$ and a maximum optical power density $W_{\max }=35 \mathrm{~mW} / \mathrm{cm}^{2}$. Hamamatsu 1336 8BQ photodiode was used to measure the radiation power density. During the measurements, the samples were on a thermostatically controlled table at a constant temperature of $300 \mathrm{~K}$. The voltage at the sample contacts during the measurement did not exceed $U=1 \mathrm{~V}$.

\section{Results and discussion}

\subsection{Crystal structure}

As shown by SEM images taken in the mode of elastically reflected electrons detection (Fig. 1), the surface of both as-deposited and after sulfur annealing at various temperatures films is developed with a granular structure.

As shown by the statistical analysis of images using the Image J software (Schneider et al., 2012; Mazzoli and Favoni, 2012), an increase in annealing temperature to leads to an increase in the size of granules: for as-deposited film average size is $\sim 70 \mathrm{~nm}$, for annealed at $200{ }^{\circ} \mathrm{C}$ is $\sim 110 \mathrm{~nm}$, at $250{ }^{\circ} \mathrm{C}$ is $\sim 140 \mathrm{~nm}$ and at $350{ }^{\circ} \mathrm{C}$ is $\sim 180 \mathrm{~nm}$. In general as is known, the rate of grain growth is proportional to the mobility of grain boundaries, which has an activation mechanism and consequently obeys the Arrhenius dependence on the temperature (Hu et al., in pressa, b).

Here, the increased annealing temperature led to migration of grains and connect with adjacent grains, consequently forms the bigger grains. According to SEM cross-sectional images, the thickness of the obtained films was observed to be varied in the range, $260-320 \mathrm{~nm}$.

Fig. 2 shows diffraction patterns of $\operatorname{In}_{2} \mathrm{~S}_{3}$ films with subtracted background and normalized to the intensity of highest peak. Colored markers represent the positions and intensities of the peaks for the corresponding phases.

Analysis of the diffraction patterns for the as-deposited and annealed at $200{ }^{\circ} \mathrm{C}$ films (Fig. 2) showed that the peaks at $2 \theta=17.08^{\circ}, 18.62^{\circ}$, $32.86^{\circ}$ are related to (112), (105), (1011) planes of modified tetragonal $\beta$-In $\mathrm{S}_{3}$ phase (JCPDS reference no. 01-080-6324). The peaks obtained at $2 \theta=21.52^{\circ}, 24.99^{\circ}, 26.01^{\circ}, 45.1^{\circ}, 46.45^{\circ}$ and $47.6^{\circ}$ are related to (221), (222), (023), (611), (026) and (145) cubic modification of $\mathrm{In}_{5} \mathrm{~S}_{4}$ phase (JCPDS reference no. 01-073-0844). Thus, it can be noted that the as-deposited and annealed in sulfur vapor at $200{ }^{\circ} \mathrm{C}$ films are characterized by relatively low crystallinity and are a mixture of at least two phases: the cubic modification of $\operatorname{In}_{5} \mathrm{~S}_{4}$ and the tetragonal modification of $\beta-\operatorname{In}_{2} S_{3}$.

Analysis of position and intensity of the peaks after annealing the films in sulfur vapor at temperatures of $250{ }^{\circ} \mathrm{C}$ and $300{ }^{\circ} \mathrm{C}$ showed good agreement with the tetragonal modification $\beta-\mathrm{In}_{2} \mathrm{~S}_{3}$ (JCPDS reference no. 01-080-6324). However, (112) characteristic peak of tetragonal modification $\beta-\operatorname{In}_{2} S_{3}$ was turned out to be very insignificant in intensity with increase of annealing temperature. This fact may indicate both the presence of film texture and cubic modification $\operatorname{In}_{2} \mathrm{~S}_{3}$ phase (JCPDS reference no.01-084-1385) after sulfur annealing at such temperatures.

The crystallographic parameters such as inter planner spacing $(d)$ and lattice constants ( $a$ and $c$ ) were calculated according to the preferred (109) plane of films annealed at $250{ }^{\circ} \mathrm{C}$ and $300{ }^{\circ} \mathrm{C}$. The lattice parameters of tetragonal phase were evaluated from the relation concerned and inter planner spacing was calculated using Bragg's diffraction law

$\frac{1}{d^{2}}=\frac{h^{2}+k^{2}}{a^{2}}+\frac{l^{2}}{c^{2}}$

$n \lambda=2 d \sin \theta$,

where $h, k, l$ are Miller indices of the lattice plane, $n$ is the integer, $\lambda=$ $0.154078 \mathrm{~nm}$ is wavelength of incident radiation and $\theta$ is Bragg's angle.

For the most intense diffraction peak $\left(2 \theta=27.423^{\circ}\right) d=0.325 \mathrm{~nm}, a$ $=0.761 \mathrm{~nm}$ and $c=3.231 \mathrm{~nm}$ are found. The size of coherent scattering region $(L)$ of the annealed films was calculated using Debye-Scherrer 


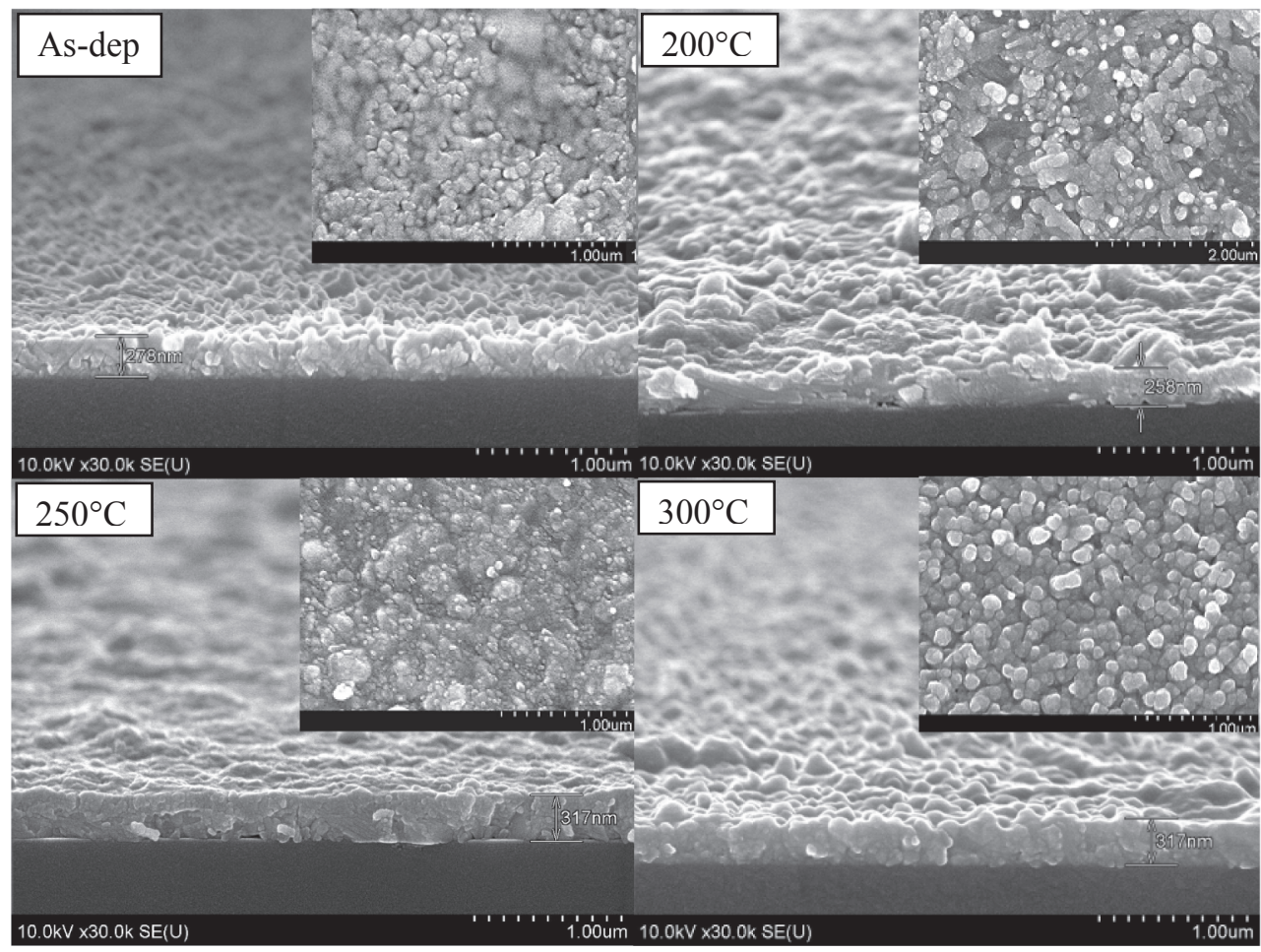

Fig. 1. Surface and cross-sectional SEM images of $\mathrm{In}_{2} \mathrm{~S}_{3}$ films (mode of elastically reflected electrons detection).

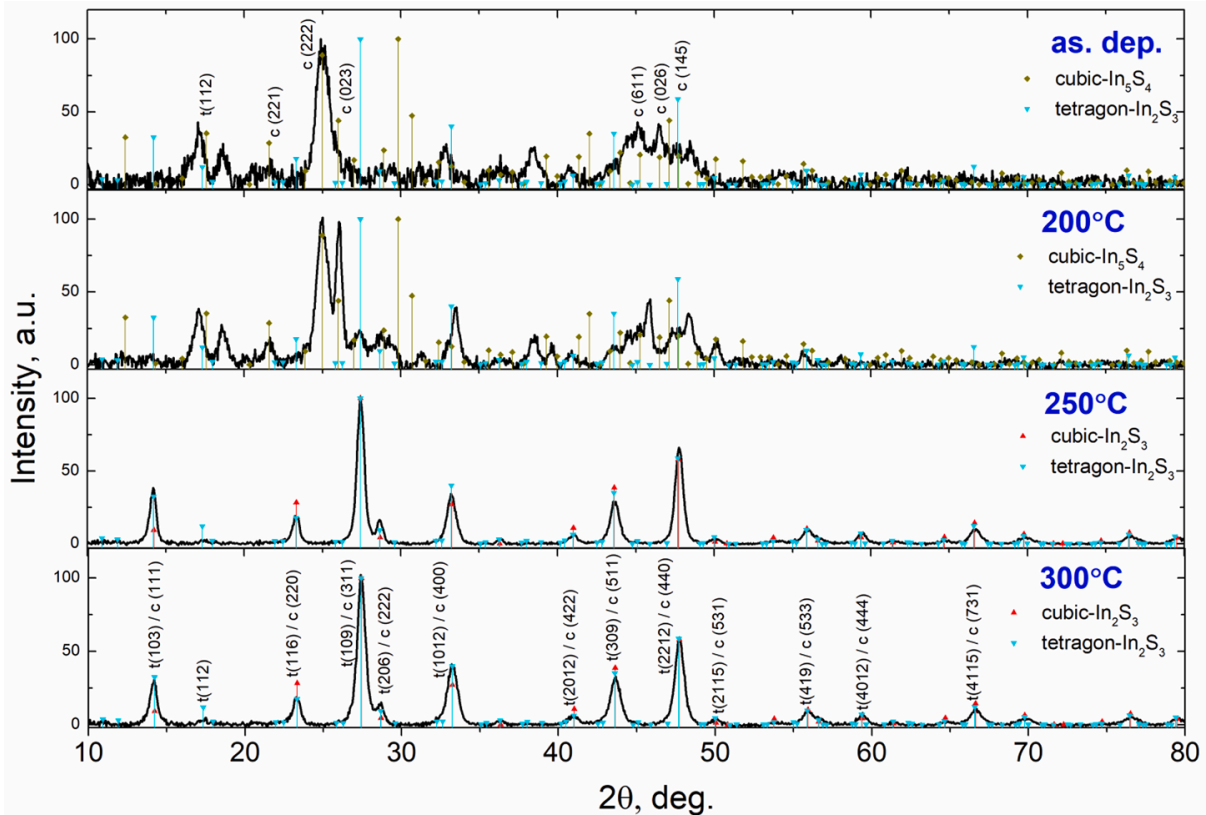

Fig. 2. X-ray diffraction of $\operatorname{In}_{2} \mathrm{~S}_{3}$ thin films depending on the annealing temperature.

formula

$L=0.94 \lambda / \beta \cdot \cos \theta$,

where $\beta$ is an integral breadth of the prevailing peak in radians. The Gauss approximation of peaks was used when $\beta=(\pi / 4 \ln 2)^{1 / 2} \times F W H M$, where FWHM is full width at diffraction peak half maximum height in radians. Calculations showed that for $\beta$ - $\mathrm{In}_{2} \mathrm{~S}_{3}$ films after annealing in sulfur atmosphere at $T_{\mathrm{s}}=250{ }^{\circ} \mathrm{C}$ and $T_{\mathrm{s}}=300{ }^{\circ} \mathrm{C}$, the average crystallite size was $14 \mathrm{~nm}$ and $13 \mathrm{~nm}$, respectively.
The elemental atomic percentages of In and $S$ in the films with

Table 1

EDX elemental analysis of $\operatorname{In}_{2} \mathrm{~S}_{3}$ films depending on the annealing temperature.

\begin{tabular}{llll}
\hline$T_{\mathrm{S}}\left({ }^{\circ} \mathrm{C}\right)$ & In (at \%) & $\mathrm{S}($ at $\%)$ & S/In ratio \\
\hline As-grown & 49.6 & 50.4 & 1.0 \\
200 & 48.4 & 51.6 & 1.1 \\
250 & 37.5 & 62.5 & 1.7 \\
300 & 36.8 & 63.2 & 1.7 \\
\hline
\end{tabular}


respect to annealing temperature are given in Table 1 . It is seen that the films of as-deposited and annealed at $200{ }^{\circ} \mathrm{C}$, the S/In ratio is close to 1 , which indicates the presence of sulfur deficiency and is in good agreement with XRD results (Fig. 2). The films deposited at substrate temperature of $350{ }^{\circ} \mathrm{C}$ contained sulfur deficiency due to re-evaporation of the sulfur from the films, owing to its high volatility (Revathi et al., 2008). While the films annealed at higher temperatures, the S/In ratio increases to 1.7, which is slightly higher than the stoichiometric for the $\beta$-In $\mathrm{S}_{2} \mathrm{~S}_{3}$ phase. At higher annealing temperatures, a rapid reaction of sulfur vapor with indium atoms which favors the grain growth and high rate of elemental sulfur diffusion in the as-deposited $\operatorname{In}_{2} \mathrm{~S}_{3}$ films. Consequently, the films contain sulfur rich at higher annealing temperatures. Bouabid et al. (Bouabid et al., 2007) also observed S/In value of 1.67 for $\mathrm{In}_{2} \mathrm{~S}_{3}$ films anealed at $573 \mathrm{~K}$ under sulfur atmosphere.

The results of Raman spectroscopy of $\mathrm{In}_{2} \mathrm{~S}_{3}$ films are presented in Fig. 3. Both for as-grown and sulfur annealed films at $T_{\mathrm{s}}=200{ }^{\circ} \mathrm{C}$, a series of wide peaks are observed indicating a high degree of disorder of the material structure. Small distinguishable peaks centered at 102 $\mathrm{cm}^{-1}, 128 \mathrm{~cm}^{-1}$ and $161 \mathrm{~cm}^{-1}$ can be attributed to the presence of $\operatorname{In}_{2} \mathrm{O}_{3}$ phase (Berengue et al., 2010; Liu et al., 2013; Kranert et al., 2014), whose characteristic peaks are not appeared in diffraction patterns indicating that $\operatorname{In}_{2} \mathrm{O}_{3}$ phase is present only on the surface. A small peak present at $480 \mathrm{~cm}^{-1}$ corresponds to the $\mathrm{S}-\mathrm{S}$ bond (Trofimov et al., 2009).

The Raman peaks intensity of as-grown and annealed films at $T_{\mathrm{S}}=$ $200{ }^{\circ} \mathrm{C}$ was increased due to the effect of resonance enhanced intensity of Raman scattering (Strommen and Nakamoto, 1977). As will be shown in part "Optical properties", band gap for direct allowed transitions is close to the Raman excitation photon energy in case of as-grown and annealed at $T_{\mathrm{s}}=200{ }^{\circ} \mathrm{C}$ films. And with an increase in the annealing temperature of films, the value of the band gap for direct allowed transitions differs more from the value of the Raman excitation energy.

Further, the films annealed at $T_{\mathrm{s}}=250{ }^{\circ} \mathrm{C}$ and $T_{\mathrm{s}}=300{ }^{\circ} \mathrm{C}$ leads to the appearance of relatively weak peaks in the spectra at $73 \mathrm{~cm}^{-1}, 246$ $\mathrm{cm}^{-1}, 267 \mathrm{~cm}^{-1}, 307 \mathrm{~cm}^{-1}$ and $367 \mathrm{~cm}^{-1}$. A comparison of the spectra of the films annealed at temperatures of $250{ }^{\circ} \mathrm{C}$ and $300{ }^{\circ} \mathrm{C}$ with the spectrum of pure high quality $\beta-\operatorname{In}_{2} \mathrm{~S}_{3}$ crystal obtained by the Bridgeman-Stockbarger method and described in works (Choe et al., 2001; Bodnar and Polubok, 2014) indicates an increase in the degree of crystallinity of the films and confirms the formation of $\beta-\operatorname{In}_{2} S_{3}$ phase. In addition, the characteristic peaks of $\operatorname{In}_{2} \mathrm{O}_{3}$ phase disappear, which may be due to the replacement of oxygen by sulfur.

\subsection{Optical properties}

Fig. 4 shows the optical transmission and specular reflection spectra

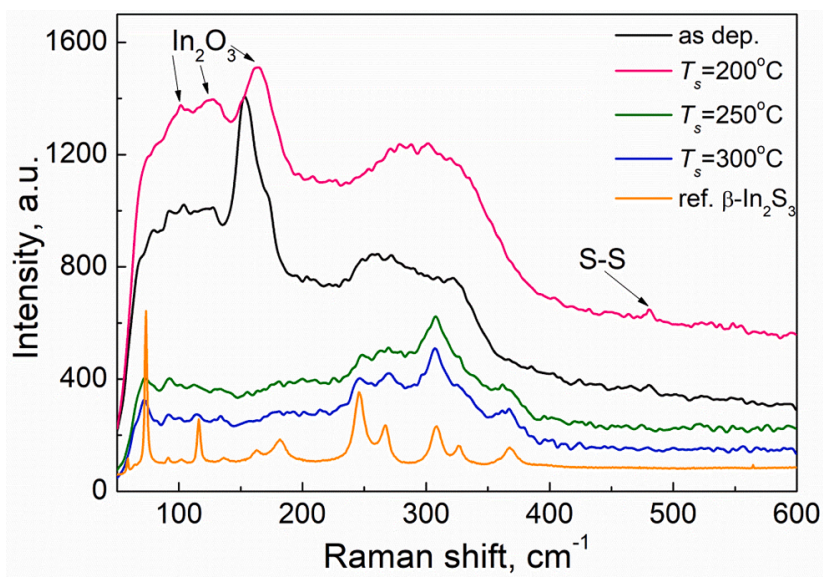

Fig. 3. Raman spectra of $\operatorname{In}_{2} \mathrm{~S}_{3}$ thin films before and after sulfur heat treatment at different temperatures as well referent $\beta$ - $\operatorname{In}_{2} S_{3}$ single crystal.

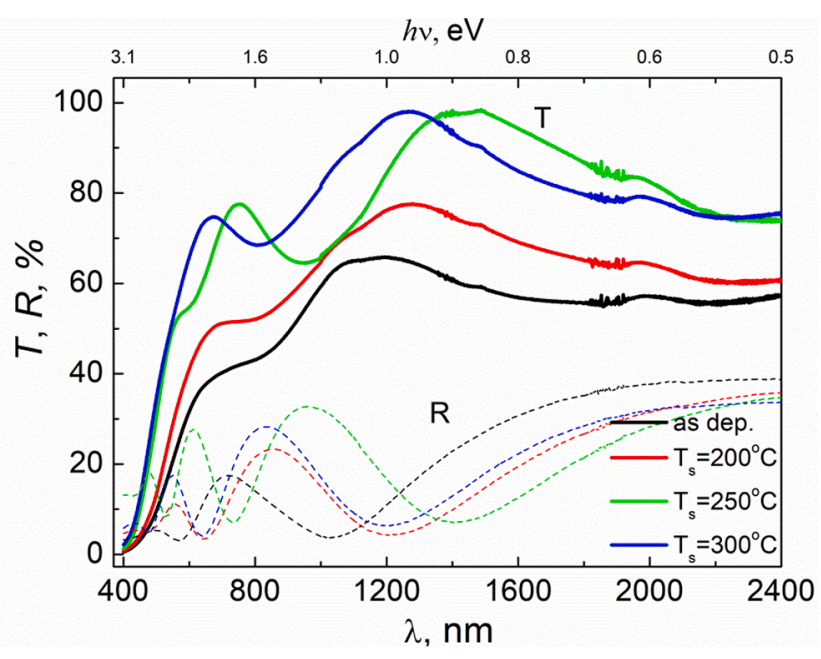

Fig. 4. Transmittance and reflection spectra of $\operatorname{In}_{2} S_{3}$ films (solid lines - transmission spectra, dashed lines - reflection spectra).

of $\mathrm{In}_{2} \mathrm{~S}_{3}$ films as-deposited and after annealing at different temperatures.

As seen from the optical transmission spectra, for the as-deposited films at wavelengths exceeding $600 \mathrm{~nm}$, the transmittance takes on relatively high values (60-65\%). Subsequent annealing at temperatures of $250{ }^{\circ} \mathrm{C}$ and $300{ }^{\circ} \mathrm{C}$ leads to an increase in transmittance up to $80 \%$, which is a good indicator for use as an optical window in solar cells.

From the transmittance and reflection spectra, the absorption coefficient $(\alpha)$ was calculated according to a formula that takes into account multiple internal reflections in a plane-parallel sample:

$\alpha=-\frac{1}{d} \ln \left(\frac{\sqrt{(1-R)^{4}+4 T^{2} R^{2}}-(1-R)^{2}}{2 T R^{2}}\right)$,

where $d$ is the thickness of the films, $T$ and $R$ are the transmittance and reflectance respectively.

The calculated absorption spectra of the $\operatorname{In}_{2} \mathrm{~S}_{3}$ films are shown in Fig. 5. As seen, for the as-deposited and annealed at $T_{\mathrm{s}}=200{ }^{\circ} \mathrm{C}$ films, the optical absorption coefficient within the spectral range of solar radiation assumes quite high values $\left(\alpha>10^{5} \mathrm{~cm}^{-1}\right)$. As the annealing temperature rises above $200{ }^{\circ} \mathrm{C}$, the optical absorption coefficient decreases by a factor of 1.5-2.0, and the absorption edge shifts noticeably toward the short-wavelength region, indicating an increase in the band gap.

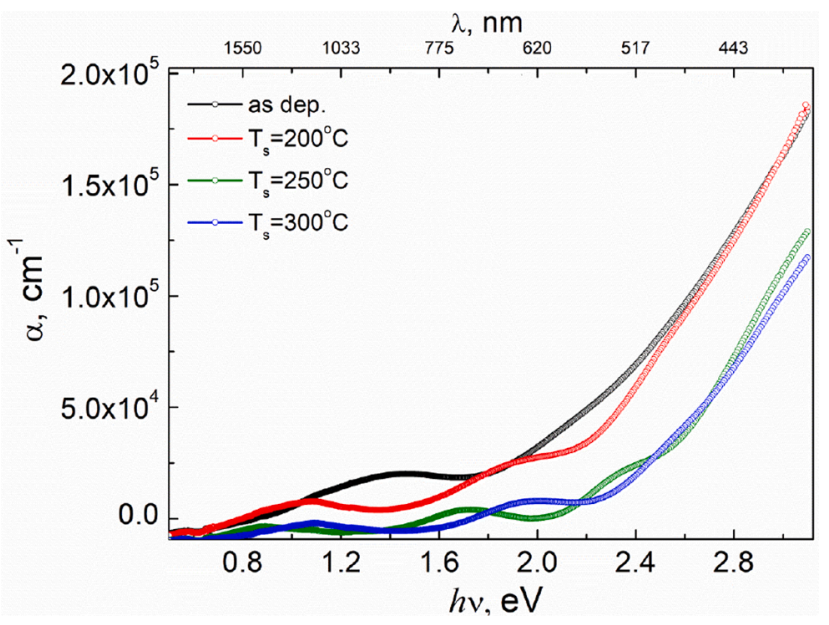

Fig. 5. Absorption spectra of $\operatorname{In}_{2} \mathrm{~S}_{3}$ films before and after annealing at various temperatures. 
It is known that the optical absorption at interband transitions, as a rule, increases according to the power law when the energy of the radiation quanta exceeds the semiconductor band gap. The optical band gap energy $\left(E_{\mathrm{g}}\right)$ can be determined from the following expression by rearranging the spectral dependence of the absorption coefficient in the Tauc coordinates and extrapolating the linear portion of the $(\alpha h \nu)^{1 / \mathrm{r}}$ dependence to zero:

$(\alpha h v)^{1 / r}=A\left(h v-E_{g}\right)$,

here $r=1 / 2$ for direct allowed transitions, $r=3 / 2$ for direct forbidden transitions, $r=2$ for indirect allowed transitions, $r=3$ for indirect forbidden transitions.

Fig. 6 shows the spectral dependences of the absorption coefficient in Tauc coordinates and observed that the $\mathrm{In}_{2} \mathrm{~S}_{3}$ films had linearization regions with an exponent of $r=2$ and $r=1 / 2$, which indicates the existence of indirect and direct allowed transitions, respectively. Moreover, with an increase in the annealing temperature from $200{ }^{\circ} \mathrm{C}$ to $300{ }^{\circ} \mathrm{C}$, the band gap for indirect allowed transitions increases from 1.6 $\mathrm{eV}$ to $2.0 \mathrm{eV}$ and for direct allowed transitions the band gap increases from $2.5 \mathrm{eV}$ to $2.7 \mathrm{eV}$. The observed enhancement in energies of direct and indirect transitions upon annealing temperature is due to the improvement in the crystallinity and less defects of the annealed films compared to the as-grown films (Revathi et al., (2010) 1487.).

The PL study revealed the absence of PL-peaks both for the initial film and for annealed at $T_{\mathrm{s}}=200{ }^{\circ} \mathrm{C}$ films. However with an increase in the annealing temperature, an insignificant photoluminescence band appears and increases in intensity at $T_{\mathrm{s}}=300^{\circ} \mathrm{C}$. In Fig. 7, the PL spectra of $\mathrm{In}_{2} \mathrm{~S}_{3}$ films annealed at $300{ }^{\circ} \mathrm{C}$ and pure high quality $\beta$ - $\operatorname{In}_{2} \mathrm{~S}_{3}$ crystal
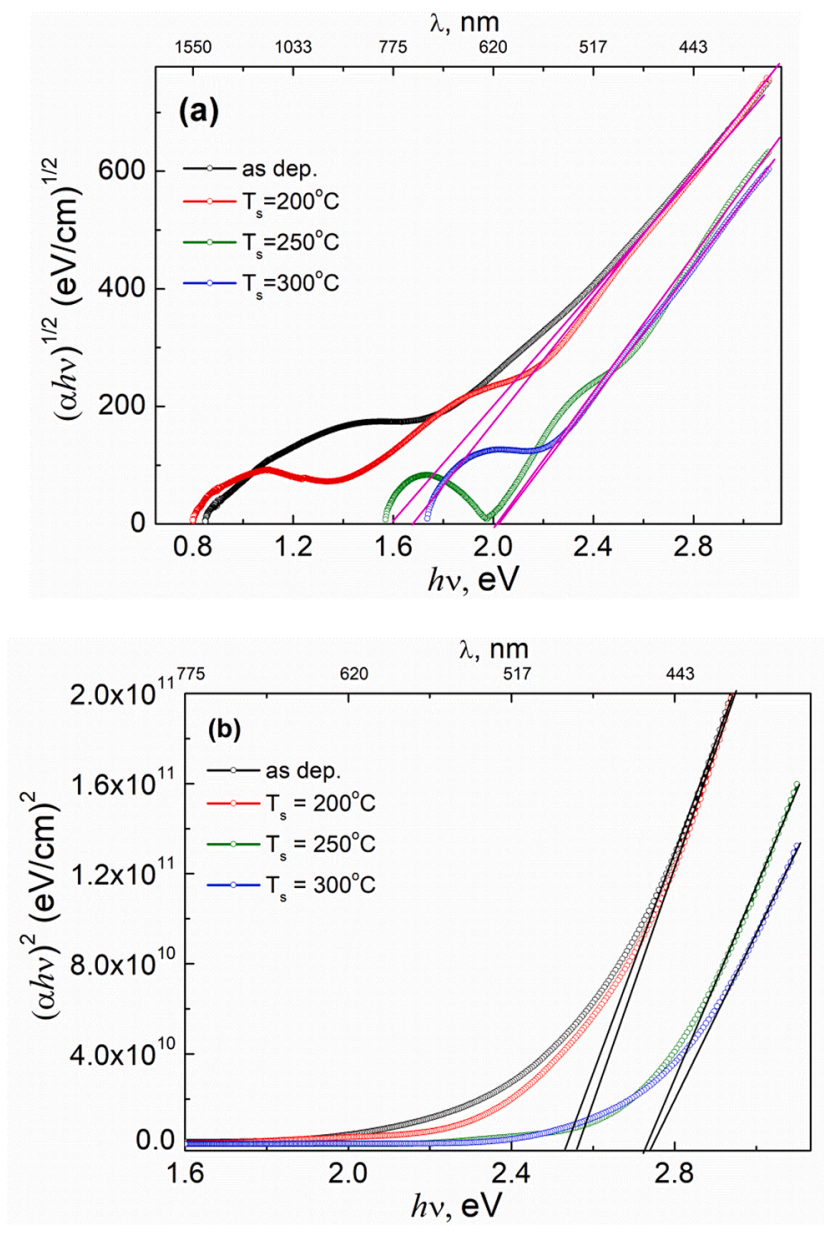

Fig. 6. Tauc plots of $\mathrm{In}_{2} \mathrm{~S}_{3}$ films for (a) indirect allowed (b) direct allowed transitions.
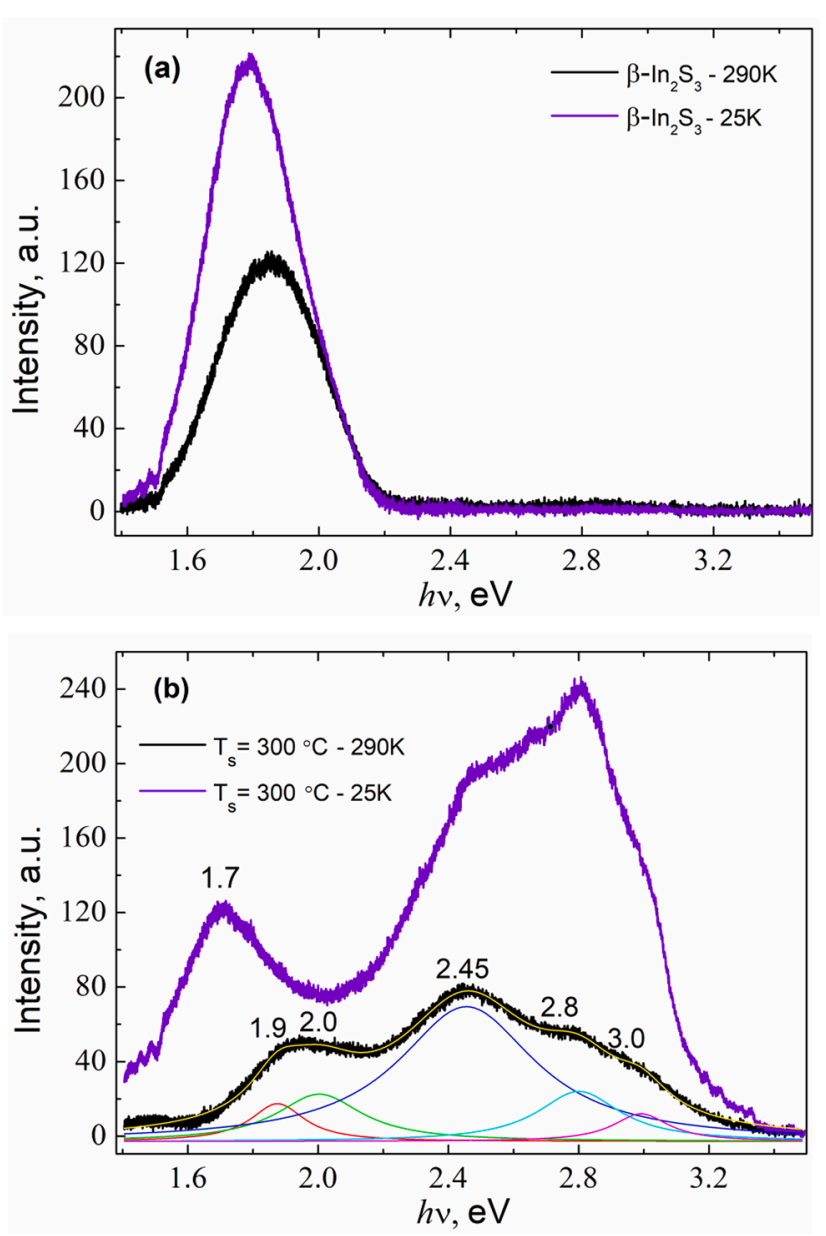

Fig. 7. PL spectra of $\beta$-In $\mathrm{In}_{2} \mathrm{~S}_{3}$ single crystal (a) and $\mathrm{In}_{2} \mathrm{~S}_{3}$ thin films annealed at $300{ }^{\circ} \mathrm{C}(\mathrm{b})$, measured at $25 \mathrm{~K}$ and $290 \mathrm{~K}$.

measured at temperatures of $295 \mathrm{~K}$ and $25 \mathrm{~K}$ are presented. As seen from Fig. $7 \mathrm{a}$, for the $\beta$ - $\operatorname{In}_{2} S_{3}$ crystal at room temperature, a significant peak was observed at $1.84 \mathrm{eV}$, which, upon cooling to $25 \mathrm{~K}$, shifts by $0.05 \mathrm{eV}$ towards decreasing energy and increases in intensity. This behavior is associated with transitions between sulfur vacancies (donors) and indium vacancies (acceptors) (Ho, 2010; Ho et al., 2016).

The Lorentz approximation of PL spectrum of $\operatorname{In}_{2} \mathrm{~S}_{3}$ films allows to distinguish four main peaks (see Fig. 7b). As can be seen, in the roomtemperature PL spectrum of the film annealed at $T_{\mathrm{s}}=300{ }^{\circ} \mathrm{C}$, in addition to low-energy peaks at $1.9-2.0 \mathrm{eV}$ associated with donor-acceptor transitions in the structure of indium sulfide, there are peaks of $2.45 \mathrm{eV}$, $2.8 \mathrm{eV}$ and $3.0 \mathrm{eV}$ which can correspond to emission from oxidized surface due to $\beta-\mathrm{In}_{2} \mathrm{~S}_{3-3 \mathrm{x}} \mathrm{O}_{3 \mathrm{x}}$ (Ho et al., 2016; Barreau et al., 2002). At the temperature of $25 \mathrm{~K}$, the intensity of these peaks increases.

Thus, based on the analysis of the dependences of the absorption coefficient in the Tauc coordinates and the PL spectra, it can be assumed that the $\operatorname{In}_{2} \mathrm{~S}_{3}$ films we obtained are an indirect-gap semiconductor with a band gap of 1.6-2.0 eV. Direct transitions in the 2.4-2.8 eV range can be attributed to the $\operatorname{In}_{2} \mathrm{~S}_{3-3 x} \mathrm{O}_{3 x}$ phase. This conclusion seems quite appropriate, since an oxide phase is present in the initial films and the granular polycrystalline structure of films with a coherent scattering region size of about $15 \mathrm{~nm}$ (due to the large number of grain boundaries) promotes oxygen diffusion along the boundaries and the formation of an indium oxysulfide phase on the surface and interfaces.

\subsection{Electrophysical properties}

Fig. 8 shows the temperature dependences of dark resistance of $\operatorname{In}_{2} \mathrm{~S}_{3}$ 


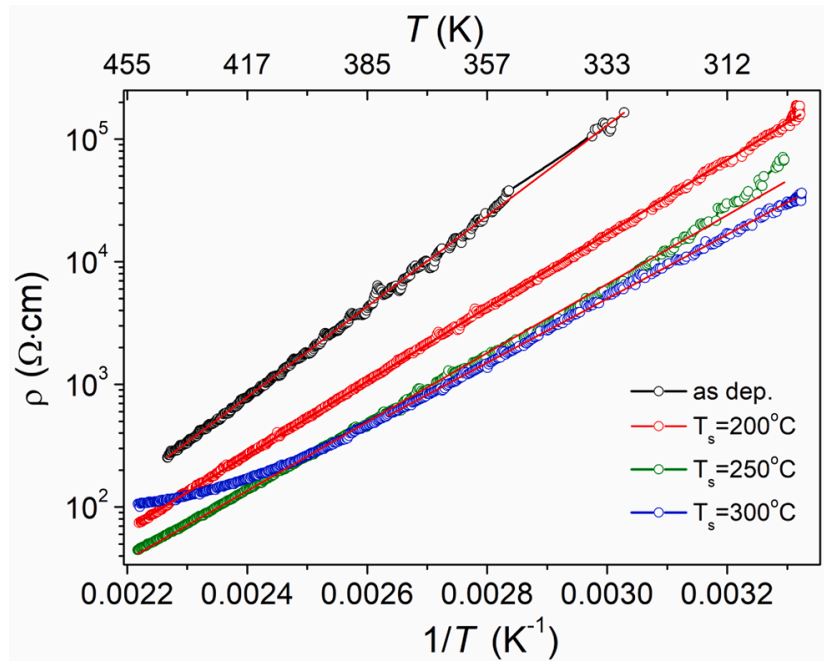

Fig. 8. Temperature dependences of the dark resistance of $\operatorname{In}_{2} S_{3}$ films.

films in Arrhenius coordinates. Linearization of the temperature dependences of the dark resistance in Arrhenius coordinates indicates an activation mechanism of electron transport with constant activation energy, $E_{a}$.

The resistivity in this case is determined by the expression:

$\rho=\rho_{0} \exp \left[E_{a} / k T\right]$,

where $\rho_{0}$ is the characteristic resistivity, $k$ is the Boltzmann constant and $T$ is temperature. Fig. 9 shows the variation of resistivity $(\rho)$ of $\operatorname{In}_{2} \mathrm{~S}_{3}$ films with annealing temperature. As the annealing temperature increased, the resistivity of the films decreased up to one order. This might be due to the ordered structure of the films that leads to increase the grain size and reduction in resistivity.

As seen from Table 2, the activation energy depending on the annealing temperature varies in the range of $0.51-0.73 \mathrm{eV}$ and with an increase in $T_{\mathrm{S}}$, a tendency to decrease in the activation energy was observed. This may be due to an increase in the number of deep levels involved in the transport of charge carriers, for example, the substitution of sulfur defect by oxygen with an activation energy of $E_{a}=0.82 \mathrm{eV}$ (Jayakrishnan et al., 2005). As well as, which may indicate changing the ratio of the number of deep levels $0.52 \mathrm{eV}, 0.64 \mathrm{eV}$ and $0.95 \mathrm{eV}$ of $\mathrm{V}_{\text {In }}$ (Ghorbani and Albe, 2018) associated with an enrichment of films with sulfur at higher annealing temperatures (Table 1).

To study the photoconductivity of the films, the resistance was

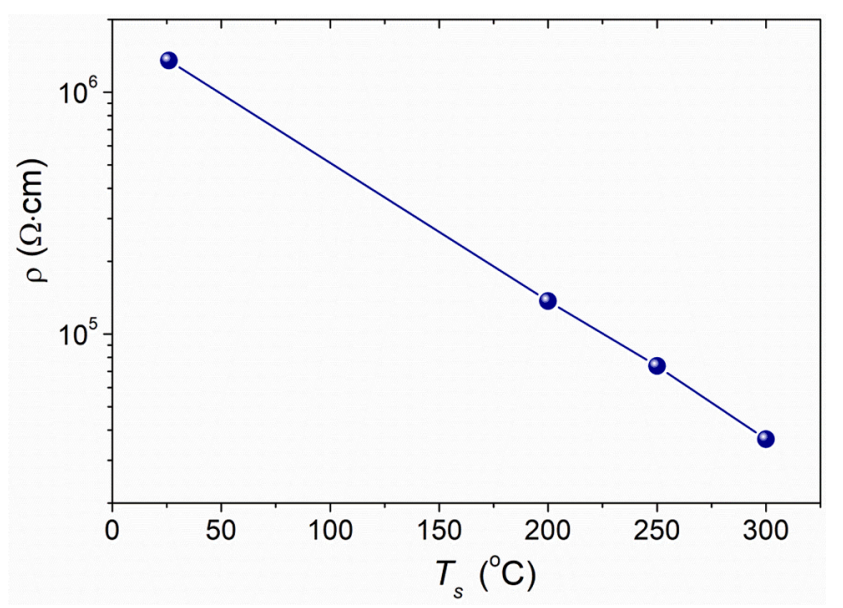

Fig. 9. Variation of resistivity at room temperature with annealing temperature.
Table 2

The calculated values of characteristic resistivity and activation energy of $\operatorname{In}_{2} \mathrm{~S}_{3}$ films.

\begin{tabular}{lll}
\hline$T_{\mathbf{s}}\left({ }^{\circ} \mathbf{C}\right)$ & $\rho_{\mathbf{0}}(\boldsymbol{\Omega} \cdot \mathrm{cm})$ & $\boldsymbol{E}_{\boldsymbol{a}}(\mathrm{eV})$ \\
\hline as-dep. & $1.09 \times 10^{-4}$ & 0.73 \\
200 & $1.56 \times 10^{-3}$ & 0.60 \\
250 & $2.50 \times 10^{-3}$ & 0.56 \\
300 & $7.26 \times 10^{-3}$ & 0.51 \\
\hline
\end{tabular}

measured under dark and illuminated by an LED with a wavelength $\lambda=$ $465 \mathrm{~nm}$. It was found that for the as-deposited indium sulfide films, photoconductivity was practically absent, while for annealed films, a significant change in the conductivity under illumination was observed. The dependences of the relative photoconductivity on the illumination intensity of the annealed films are shown in Fig. 10.

From Fig. 10, the dependences of relative photoconductivity of $\operatorname{In}_{2} \mathrm{~S}_{3}$ films are linearized on a double logarithmic scale, which indicates a power-law dependence of the form:

$\Delta G / G_{0}=S^{\gamma}$,

where $\Delta G=G-G_{0}$ is the change in photoconductivity under illumination, $G_{0}$ is the dark conductivity of films.

Table 3 presents the calculated values of relative photoconductivity at $S_{\max }=35 \mathrm{~mW} / \mathrm{cm}^{2}$ and coefficient $(\gamma)$ for $\mathrm{In}_{2} \mathrm{~S}_{3}$ samples with different annealing temperatures.

From the Table 3 , it is observed that the films annealed at $T_{\mathrm{s}}=$ $200{ }^{\circ} \mathrm{C}$, the photosensitivity is low and the exponent is close to 0.5 , which indicates the realization of a high level of excitation of nonequilibrium charge carriers when the concentration of nonequilibrium charge carriers significantly exceeds the equilibrium one.

Quite large values of the relative photoconductivity are observed in $\mathrm{In}_{2} \mathrm{~S}_{3}$ films annealed in a sulfur atmosphere at $250^{\circ} \mathrm{C}$ and $300{ }^{\circ} \mathrm{C}$, while the coefficient $\gamma$ takes values close to 1.0. This fact indicates the realization of a low level of excitation, when the concentration of nonequilibrium charge carriers generated by the radiation is much less than the concentration of equilibrium ones. This correlates well with a decrease in the dark resistance of $\beta$-In ${ }_{2} S_{3}$ films and an increase in the optical band gap after sulfur annealing.

\section{Conclusion}

Changes occurred in the structural, optical and electrical properties of thermally evaporated $\operatorname{In}_{2} \mathrm{~S}_{3}$ films upon annealing in sulfur vapour have been studied. SEM analysis showed that the films have a granular

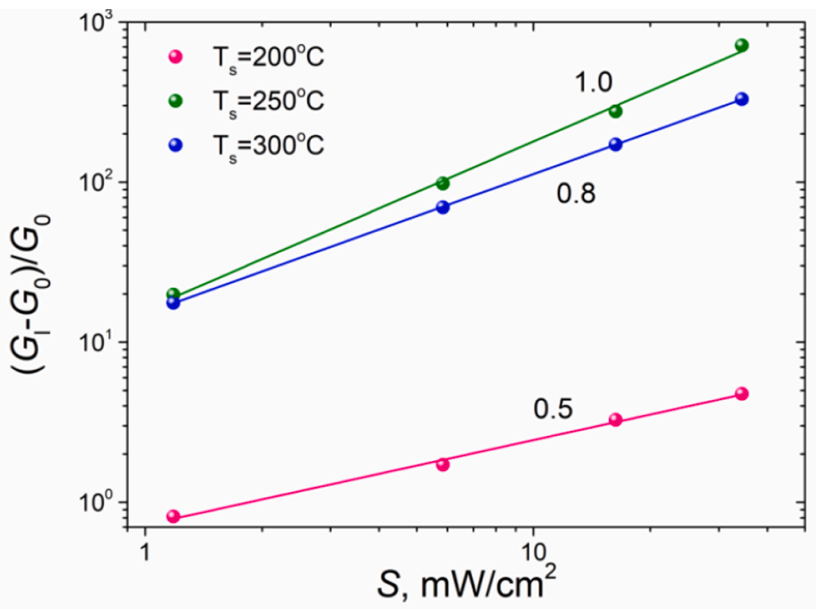

Fig. 10. Variation of photosensitivity of $\operatorname{In}_{2} \mathrm{~S}_{3}$ films with different annealing temperature from light intensity. 
Table 3

The relative photoconductivity and the coefficient of slope of the photosensitivity from light intensity.

\begin{tabular}{lll}
\hline$T_{\mathbf{s}}\left({ }^{\circ} \mathbf{C}\right)$ & $\Delta G / G_{\mathbf{0}}$ & $\gamma$ \\
\hline as dep. & 0 & - \\
200 & 4.7 & 0.52 \\
250 & 713 & 1.0 \\
300 & 329 & 0.87 \\
\hline
\end{tabular}

structure, the size of granules enhanced with increase in annealing temperature. According to the EDX analysis, the S/In ratio varies from less than stoichiometric to slightly higher than stoichiometric. The GIXD patterns revealed that the as-deposited and annealed in sulfur vapor at low temperature films are characterized by low crystallinity and mixture of cubic $\operatorname{In}_{5} S_{4}$ phase and tetragonal $\beta$ - $\operatorname{In}_{2} S_{3}$ phase. As the annealing temperature increase leads to an improvement in the crystallinity of the films and the formation of tetragonal $\beta$ - $\operatorname{In}_{2} \mathrm{~S}_{3}$ phase. A comparison of the Raman spectra of the films with the spectrum of pure high quality $\beta-\mathrm{In}_{2} \mathrm{~S}_{3}$ crystal indicates an increase in the degree of crystallinity of the films and confirms the formation of $\beta$ - $\operatorname{In}_{2} S_{3}$ phase with increase of annealing temperature. In addition, the characteristic peaks of $\operatorname{In}_{2} \mathrm{O}_{3}$ phase disappear. The spectral dependences of the absorption coefficient in Tauc coordinates indicates the existence of indirect and direct allowed transitions, with an increase in the annealing temperature from $200{ }^{\circ} \mathrm{C}$ to $300{ }^{\circ} \mathrm{C}$, the energy gap for indirect allowed transitions increases from $1.6 \mathrm{eV}$ to $2.0 \mathrm{eV}$ and for direct allowed transitions, the energy gap increases from $2.5 \mathrm{eV}$ to $2.7 \mathrm{eV}$. Comparison with PL spectra makes it possible to associate indirect transitions with the $\operatorname{In}_{2} \mathrm{~S}_{3}$ band gap, and direct transitions with the oxysulfide phase. The temperature dependences of dark resistance of the films in Arrhenius coordinates indicate an activation mechanism of electron transport with constant activation energy. As the annealing temperature increased, the resistivity and the activation energy value of the films decreased. For the as-deposited films, photoconductivity was practically absent and for the films annealed at $200{ }^{\circ} \mathrm{C}$, the photosensitivity was low with the realization of a high level of excitation of nonequilibrium charge carriers. With an increase in the annealing temperature, a significant increase in the relative photoconductivity is observed, which indicates an increase in the lifetime of charge carriers. In this case, it is realized that the low level of excitation at which the concentration of nonequilibrium charge carriers generated by radiation is much lower than the concentration of equilibrium carriers. This fact correlates well with a decrease in the dark resistance of $\beta$ - $\operatorname{In}_{2} \mathrm{~S}_{3}$ films and an increase in the optical band gap after sulfur annealing at higher temperature.

The present analysis revealed that the physical properties of the thermally evaporated $\mathrm{In}_{2} \mathrm{~S}_{3}$ thin films were improved with increase of annealing temperature and the films annealed under sulfur atmosphere at $300{ }^{\circ} \mathrm{C}$ showed good structural, morphological, optical and electrical properties indicating that such films are suitable as window/buffer layer in the development of polycrystalline thin film solar cell.

\section{Declaration of Competing Interest}

The authors declare that they have no known competing financial interests or personal relationships that could have appeared to influence the work reported in this paper.

\section{Acknowledgements}

This work was supported by the Dept. of Science and Technology, Govt. of India (Grant No: DST/INT/BLR/P-30/2019) and the State Committee on Science and Technology of the Republic of Belarus (Grant No: F19INDG-008). The authors are grateful to Affiliate RDC "Belmicrosystems" JSC "INTEGRAL" - "INTEGRAL" Holding Managing Company for SEM studies, and to professor Bodnar' I.V. for the provided referent $\beta-\mathrm{In}_{2} \mathrm{~S}_{3}$ single crystal.

\section{References}

Barreau, N., Marsillac, S., Albertini, D., Bernède, J., 2002. Structural, optical and electrical properties of $\beta-\operatorname{In}_{2} \mathrm{~S}_{3-3 \mathrm{x}} \mathrm{O}_{3 \mathrm{x}}$ thin films obtained by PVD. Thin Solid Films 403, 331. https://doi.org/10.1016/S0040-6090(01)01512-7.

Berengue, O.M., Rodrigues, A.D., Dalmaschio, C.J., Lanfredi, A.J.C., Leite, E.R., Chiquito, A.J., 2010. Structural characterization of indium oxide nanostructures: a Raman analysis. J. Phys. D: Appl. Phys. 43, 045401. 0022-3727/43/4/045401.

Bodnar, I.V., Gremenok, V.F., 2011. Growth and thermal expansion of $\operatorname{In}_{2} \mathrm{~S}_{3}$ single crystals. Inorg. Mater. 44, 329. https://doi.org/10.1134/S0020168508040018.

Bodnar, I.V., Polubok, V.A., 2014. Optical properties of $\operatorname{In}_{2} \mathrm{~S}_{3}$ thin films. J. Appl. Spectrosc. 81, 881. https://doi.org/10.1007/s10812-014-0022-7.

Bouabid, K., Ihlal, A., Outzourhit, A., Ameziane, E.L., 2004. Structural and optical properties of In2S3 thin films prepared by flash evaporation. Active Passive Electronic Components 27, 207, 10.1080=08827510310001648899.

Bouabid, K., Ihlal, A., Amira, Y., Sdaq, A., Outzourhit, A., Nouet, G., 2007. Effect of annealing on $\mathrm{In}_{2} \mathrm{~S}_{3}$ thin films prepared by flash evaporation. Eur. Phys. J. Appl. Phys. 40, 149. https://doi.org/10.1051/epjap:2007137.

Choe, Sung-Hyu, Bang, Tae-Hwan, Kim, Nam-Oh, Kim, Hyung-Gon, Lee, Choong-Il, Jin, Moon-Seog, Seok-Kyun, Oh., Kim, Wha-Tek, 2001. Optical properties of $\beta-\mathrm{In}_{2} \mathrm{~S}_{3}$ and $\beta-\mathrm{In}_{2} \mathrm{~S}_{3}: \mathrm{Co}^{2+}$ single crystals. Semicond. Sci. Technol. 16, 98. https://doi.org/ 10.1088/0268-1242/16/2/307.

Diehl, R., Carpentier, C., Nitsche, R., 1976. The crystal structure of $\beta-\operatorname{In}_{2} S_{3}$ stabilized by As or Sb. Acta Crystallogr. Sect. B, Struct. Crystallogr. Cryst. Chem. 32, 1257. https://doi.org/10.1107/S0567740876005062.

Ghorbani, E., Albe, K., 2018. Intrinsic point defects in $\beta-\mathrm{In}_{2} \mathrm{~S}_{3}$ studied by means of hybrid density-functional theory. J. Appl. Phys. 123, 103103 https://doi.org/10.1063/ 1.5020376.

Gu, Y., Wang, Y., 2014. Microwave hydrothermal growth of $\operatorname{In}_{2} \mathrm{~S}_{3}$ interconnected nanoflowers and nanoparticles on graphene for high-performance Li-ion batteries. RSC Adv. 4, 8582. https://doi.org/10.1039/c3ra46514d.

Ho, C.H., 2010. Growth and characterization of near-band-edge transitions in $\beta-\operatorname{In}_{2} \mathrm{~S}_{3}$ single crystals. J. Cryst. Growth 312, 2718. https://doi.org/10.1016/j. jcrysgro.2010.06.018.

Ho, Ching-Hwa, Lin, Min-Han, Wang, Yi-Ping, Huang, Ying-Sheng, 2016. Synthesis of $\mathrm{In}_{2} \mathrm{~S}_{3}$ and $\mathrm{Ga}_{2} \mathrm{~S}_{3}$ crystals for oxygen sensing and UV photodetection. Sens. Actuators, A 245, 119. https://doi.org/10.1016/j.sna.2016.05.003.

Hou, Y., Chen, X., Yang, S., Lin Zhong, Y., Li, C., Zhao, H., Gui Yang, H., 2017. Low temperature processed $\mathrm{In}_{2} \mathrm{~S}_{3}$ electron transport layer for efficient hybrid perovskite solar cells. Nano Energy 36, 102. https://doi.org/10.1016/j.nanoen.2017.04.033.

Hu, J., Wang, X., Zhang, J., Luo, J., Zhang, Z., Shen, Z., in press. A general mechanism of grain growth I: Theory. J. Materiom. Doi: 10.1016/j.jmat.2021.02.007.

Hu, J., Zhang, J., Wang, X., Luo, J., Zhang, Z., Shen, Z., in press. A general mechanism of grain growth II: Experimental. J. Materiom. Doi: 10.1016/j.jmat.2021.02.008.

Jackson, P., Wuerz, R., Haiskos, D., Lotter, E., Witte, W., Powalla, M., 2016. Effects of heavy alkali elements in $\mathrm{Cu}(\mathrm{In}, \mathrm{Ga}) \mathrm{S}_{\mathrm{e}} 2$ solar cells with efficiencies up to $22.6 \%$. Phys. Status Solidi RRL 10, 583. https://doi.org/10.1002/pssr.201600199.

Jayakrishnan, R., John, T.T., Kartha, C.S., Vijayakumar, K.P., Abe, T., Kashiwaba, Y., 2005. Defect analysis of sprayed $\beta$ - $\operatorname{In}_{2} \mathrm{~S}_{3}$ thin films using photoluminescence studies. Semicond. Sci. Technol. 20, N12. https://doi.org/10.1088/0268-1242/20/12/003.

Ji, Y., Ou, Y., Yu, Z., Yan, Y., Wang, D., Yan, C., Liu, L., Zhang, Y., Zhao, Y., 2015. Effect of film thickness on physical properties of RF sputtered $\operatorname{In}_{2} \mathrm{~S}_{3}$ layers. Surf. Coat. Technol. 276, 587. https://doi.org/10.1016/j.surfcoat.2015.06.011.

Kranert, C., Schmidt-Grund, R., Grundmann, M., 2014. Raman active phonon modes of cubic $\operatorname{In}_{2} \mathrm{O}_{3}$. Phys. Status Solidi RRL 8, 554. https://doi.org/10.1002/ pssr.201409004.

Lee, Jeoung Ju, Lee, Jong Duk, Ahn, Byeong Yeol, Kim, Kun Ho, 2008. Structural and optical properties of $\beta-\operatorname{In}_{2} \mathrm{~S}_{3}$ and $\beta-\operatorname{In}_{2} \mathrm{~S}_{3}: \mathrm{Co}^{2+}$ films prepared on indium-tin-oxide substrates. J. Korean Phy. Soc. 53, 3255. https://doi.org/10.3938/jkps.53.3255.

Lee, D., Yang, J.Y., 2021. Investigation of $\mathrm{Cu}_{2} \mathrm{ZnSnS}_{4}$ solar cell buffer layer fabricated via spray pyrolysis. Curr. Appl. Phys. 21, 184. https://doi.org/10.1016/j. cap.2020.11.003.

Li, Y., Liu, L., Feng, J., Ren, X., Zhang, Y., Yan, T., Liu, X., Wei, Q., 2020. A self-powered photoelectrochemical cathodic aptasensor for the detection of $17 \beta$-estradiol based on $\mathrm{FeOOH} / \mathrm{In}_{2} \mathrm{~S}_{3}$ photoanode. Biosensors Bioelec. 154, 112089 https://doi.org/ 10.1016/j.bios.2020.112089.

Liu, D., Lei, W., Qin, S., Hou, L., Liu, Z., Cui, Q., Chen, Y., 2013. Large-scale synthesis of hexagonal corundum-type $\mathrm{In}_{2} \mathrm{O}_{3}$ by ball milling with enhanced lithium storage capabilities. J. Mater. Chem. A 1, 5274. https://doi.org/10.1039/C3TA00182B.

Lugo-Loredo, S., Peña-Méndez, Y., Calixto-Rodriguez, M., Messina-Fernández, S., Alvarez-Gallegos, A., Vázquez-Dimas, A., Hernández-García, T., 2014. Indium sulfide thin films as window layer in chemically deposited solar cells. Thin Solid Films 550, 110. https://doi.org/10.1016/j.tsf.2013.10.115.

Mazzoli, A., Favoni, O., 2012. Particle size, size distribution and morphological evaluation of airborne dust particles of diverse woods by Scanning Electronic Microscopy and image processing program. Powder Technol. 225, 65. https://doi org/10.1016/j.powtec.2012.03.033.

Nagesh, D.K., Liang, X., Momedov, A.A., Gainer, G., Eastman, M.A., Giersig, M., Song, J. J., Ni, T., Kotov, N.A., 2001. $\operatorname{In}_{2} \mathrm{~S}_{3}$ nanocolloids with excitonic emission: $\operatorname{In}_{2} \mathrm{~S}_{3}$ vs $\mathrm{CdS}$ comparative study of optical structural characteristics. J. Phys. Chem. B 105, 7490. https://doi.org/10.1021/jp011265i.

Nehra, S.P., Chander, S., Sharma, A., Dhaka, M.S., 2015. Effect of thermal annealing on physical properties of vacuum evaporated $\mathrm{In}_{2} \mathrm{~S}_{3}$ buffer layer for eco-friendly 
photovoltaic applications. Mater. Sci. Semicond. Process. 40, 26. https://doi.org/ 10.1016/j.mssp.2015.06.049.

Pistor, Paul, Merino Alvarez, Jose M., Leon, Maximo, di Michiel, Marco, Schorr, Susan, Klenk, Reiner, Lehmann, Sebastian, 2016. Structure reinvestigation of $\alpha$-, $\beta$ - and $\gamma$-In2S3. Acta Cryst. B72, 410. https://doi.org/10.1107/S2052520616007058.

Revathi, N., Prathap, P., Subbaih, Y.P.V., Ramakrishna Reddy, K.T., 2008. Substrate temperature dependent physical properties of $\mathrm{In}_{2} \mathrm{~S}_{3}$ films. J. Phys. D: Appl. Phys. 41, 155404 https://doi.org/10.1088/0022-3727/41/15/155404.

Revathi, N., Prathap, P., Miles, R.W., Ramakrishna Reddy, K.T., 2010. Annealing effect on the physical properties of evaporated $\mathrm{In}_{2} \mathrm{~S}_{3}$ films. Sol. Energy Mater. Sol. Cells 94, 1487. https://doi.org/10.1016/j.solmat.2010.02.044.

Sandoval-Paz, M.G., Sotelo-Lerma, M., Valenzuela-Jáuregui, J.J., Flores-Acosta, M., Ramírez-Bon, R., 2005. Structural and optical studies on thermal-annealed In2S3 films prepared by the chemical bath deposition technique. Thin Solid Films 472, 5 . https://doi.org/10.1016/j.tsf.2004.05.096.

Sanz, C., Guillen, C., Gutierrez, M.T., Herrero, J., 2013. Investigation of optical, structural and chemical properties of indium sulfide thin films evaporated at low temperature by modulated flux deposition. Phys. Status Solidi A 210, 320. https:// doi.org/10.1002/pssa.201228259.

Schneider, C.A., Rasband, W.S., Eliceiri, K.W., 2012. NIH Image to ImageJ: 25 years of image analysis. Nat. Methods 9, 671. https://doi.org/10.1038/nmeth.2089.

Shi, J., Wang, Y., Yang, M., Gu, Y., An, W., Men, Y., Yang, J., Rui, Y., 2021. Enhanced interface properties of solution processed antimony sulfide planar solar cells with ntype indium sulfide buffer layer. Electrochim. Acta 376, 138031. https://doi.org/ 10.1016/j.electa.2021.138031.

Souissi, R., Bouguila, N., Labidi, A., 2018. Ethanol sensing properties of sprayed $\beta-\operatorname{In}_{2} S_{3}$ thin films. Sens. Actuators, B 261, 522. https://doi.org/10.1016/j.snb.2018.01.175.

Souissi, R., Bouguila, N., Kraini, M., Vázquez-Vázquez, C., Labidi, A., 2019. Substrate temperature effect on microstructure, oxygen adsorption and ethanol sensing response of sprayed $\operatorname{In}_{2} \mathrm{~S}_{3}$ films. J. Mater. Sci.: Mater. Electron. 30, 20069. https:// doi.org/10.1007/s10854-019-02378-7.
Souissi, R., Bouguila, N., Bendahan, M., Fiorido, T., Aguir, K., Kraini, M., VázquezVázquez, C., Labidi, A., 2020. Highly sensitive nitrogen dioxide gas sensors based on sprayed $\beta-\mathrm{In}_{2} \mathrm{~S}_{3}$ film. Sens. Actuators, B 319, 128280. https://doi.org/10.1016/j. snb.2020.128280.

Souissi, R., Bouguila, N., Bouricha, B., V́azquez-V́azquez, C., Bendahan, M., Labidi, A. 2020. Thickness effect on VOC sensing properties of sprayed In2S3 films. RSC Adv. 10, 18841. https://doi.org/10.1039/D0RA01573C.

Spiering, S., Nowitzki, A., Kessier, F., Igalson, M., Maksoud, H.A., 2016. Optimization of buffer-window layer system for CIGS thin film devices with indium sulphide buffer by in-line evaporation. Sol. Energy Mater. Sol. Cells 144, 544. https://doi.org/ 10.1016/j.solmat.2015.09.038.

Strommen, D.P., Nakamoto, K., 1977. Resonance Raman spectroscopy. J. Chem. Educ. 54, 474. https://doi.org/10.1021/ed054p474.

Trofimov, B.A., Sinegovskaya, L.M., Gusarova, N.K., 2009. Vibrations of the S-S bond in elemental sulfur and organic polysulfides: a structural guide. J. Sulfur Chem. 30, 518. https://doi.org/10.1080/17415990902998579.

Wang, X., Li, H., Zhang, J., Liu, X., Zhang, X., 2020. Wedged $\beta$ - $\mathrm{In}_{2} \mathrm{~S}_{3}$ sensitized $\mathrm{TiO}_{2}$ films for enhanced photoelectrochemical hydrogen generation. J. Alloys Compd. 831 , 154798 https://doi.org/10.1016/j.jallcom.2020.154798.

Yang, P., Tang, Q., Ji, C., Wang, H., 2015. A strategy of combining SILAR with solvothermal process for $\operatorname{In}_{2} S_{3}$ sensitized quantum dot-sensitized solar cells. Appl. Surf. Sci. 357, 666. https://doi.org/10.1016/j.apsusc.2015.09.049.

Yang, B., Wang, M., Hu, X., Zhou, T., Zang, Z., 2019. Highly efficient semitransparent CsPbIBr 2 perovskite solar cells via low-temperature processed $\mathrm{I}_{\mathrm{n}} 2_{\mathrm{s}} 3$ as electrontransport-layer. Nano Energy 57, 718. https://doi.org/10.1016/j. nanoen.2018.12.097.

Zhang, Y., Zhu, J., Liu, F., Wu, G., Wei, J., Hu, L., Huang, Y., Zhang, C., Tang, J., Dai, S., 2014. $\mathrm{In}_{2} \mathrm{~S}_{3}$ sensitized solar cells with a new passivation layer. J. Photochem. Photobiol., A 281, 53. https://doi.org/10.1016/j.jphotochem.2014.02.012. 